\title{
A COMPARISON OF THE EFFECTS OF CONTINUOUS KETAMINE INFUSION AND HALOTHANE ON OXYGENATION DURING ONE-LUNG ANAESTHESIA IN DOGS
}

\author{
Philip D. Lumb. George Silvay. Avron I. Weinreich and Howard Shiang
}

ONE LUNG VENTILATION with high inspired oxygen fraction and a volatile anaesthetic agentmuscle relaxant sequence is a commonly used technique for endobronchial anaesthesia for pul. monary resection and has been associated with significant arterial hypoxaemia in 15 to 25 per cent of cases.' The major determinant of the hypoxacmia is continued perfusion in the nonventilated lung. ${ }^{2}$ Contributory causes are:

(1) abolition of the hypoxic vasoconstrictive reflex by inhalational agents; ${ }^{3}$ (2) direct myocardial depression consequent on the use of halothane, which causes a decrease in total cardiac output without parallel changes in shunt; (3) atelectatic areas in the dependent ventilated and perfused lung; ${ }^{2}$ (4) possible increase in absorption atelectasis due to high inspired oxygen concentration: ${ }^{4}(5)$ increase in shunt fraction due to positive pressure ventilation..$^{5,6}$

This experiment was designed to study the effects of a continuous infusion of ketamine on $\mathrm{Pa}_{\mathrm{U}_{2}}$. cardiac output and shunt fraction during one lung anaesthesia compared with the effects of halothane under similar experimental conditions.

\section{METHOD}

Six mongrel dogs weighing $21-28 \mathrm{~kg}$ were anaesthetized with an intravenous injection of sodium pentobarbitone $4 \mathrm{mg} \cdot \mathrm{kg}^{-1}$, intubated with a cuffed Gordon-Greene endobronchial tube and paralyzed with d-tubocurarine at an initial dose of $0.2 \mathrm{mg} \cdot \mathrm{kg}^{-1}$. Supplemental doses of 0.1 $\mathrm{mg} \cdot \mathrm{kg}^{-1}$ were given as necessary but never within 15 minutes of a measurement. (Although

Philip D. Lumb, M.B.B.S.. Clinical Instructor in Anesthesiology; George Silvay, M.D. Ph.D.. Associate Professor of Clinical Anesthesia, Associate Attending Anesthesiologist: Avron I, Weinreich, M.D. Associate Professor of Clinical Anesthesia, Associate Attending Anesthesiologist; Howard Shiang, D.V.M. Assistant in Surgery. Division of Cardiothoracic Surgery. From the Departments of Anesthesiology and the Division of Cardiothoracic Surgery of the Department of Surgery. The Mount Sinai School of Medicine of the City University of New York, and The Mount Sinai Hospital and Medical Center, One Gustave Levy Place, New York. New York. 10029. the Gordon-Greene endobronchial tube is a long. right-sided single lumen device, it was chosen because it enabled ventilation of both lungs with ease, and, at appropriate times, the extra length was employed when the tube was advanced into the lung to be inflated, so ensuring total isolation of the unventilated lung.) The femoral artery was cannulated and the chest was opened by a median sternotomy. The right atrium and pulmonary artery were cannulated directly and left atrial pressures were obtained by puncture of the left atrium with a 21-gauge needle. All cannulae were attached to Statham P 23 ID transducers and continuously flushed using a Sorenson MK-3-40 monitoring set. Pressures, waveforms and lead II of the electrocardiogram were continuously displayed on an Electronics for Medicine Physiological monitoring and recorder system.

The dogs were ventilated with oxygenenriched air mixtures using a Bennett MA-1 ventilator at 12 breaths per minute with a tidal volume of $10-12 \mathrm{ml} / \mathrm{kg}$. Inspired oxygen fraction was continuously monitored with an Instrumentation Laboratories 1. L. 404 oxygen analyzer and halothane was added at appropriate times using a Fluotec Mark II vaporiser incorporated into the inspiratory limb of the breathing circuit.

In each dog, control values were obtained with pentobarbital-curare-oxygen anaesthesia alone and these values were then compared with the effects due first to ketamine and second to halothane in all dogs. (Table I indicates the experimental flow pattern.) The dogs were allowed to stabilize with each anaesthetic agent at 50 per cent and 100 per cent inspired oxygen and also during one and two lung anaesthesia. No attempt was made to selectively collapse the right or left lung initially; but subsequently the same lung was collapsed throughout the individual experiments. Blood was withdrawn from the femoral and pulmonary arteries at specified times during the experiment and determinations of $\mathrm{pH}, \mathrm{PO}_{2}, \mathrm{PCO}_{2}$. base excess, standard base excess, and haematocrit were made. Saturation was measured directly with an Instrumentation Laboratories 182 co-oximeter. Cardiac output was measured as 394

Canad. Anaesth. Soc, J., vol. 26, no. 5, September 1979 
TABLE I

EXPerimental PatTern and Schema of Sampling Order

\begin{tabular}{|c|c|c|c|}
\hline \multicolumn{4}{|c|}{ Sampling order } \\
\hline $\begin{array}{c}\text { Pentobarbi } \\
\begin{array}{c}\text { C1 } \\
\text { C2 } \\
\text { C3 } \\
\text { C4 } \\
\text { C5 }\end{array}\end{array}$ & $\begin{array}{l}\text { are } \\
21 \% \text { oxygen } \\
50 \% \text { oxygen } \\
100 \% \text { oxygen } \\
100 \% \text { oxygen } \\
50 \% \text { oxygen }\end{array}$ & $\begin{array}{l}\text { both lungs } \\
\text { both lungs } \\
\text { both lungs } \\
\text { one lung } \\
\text { one lung }\end{array}$ & $\begin{array}{l}\text { cardiac output } 1 \\
\text { cardiac output } 2 \\
\text { cardiac output } 3\end{array}$ \\
\hline $\begin{array}{c}\text { Ketamine } \\
\mathbf{K} \mathbf{1} \\
\mathbf{K} 2 \\
\mathbf{K} 3 \\
\mathbf{K} 4\end{array}$ & $\begin{array}{r}50 \% \text { oxygen } \\
100 \% \text { oxygen } \\
100 \% \text { oxygen } \\
50 \% \text { oxygen }\end{array}$ & $\begin{array}{l}\text { one lung } \\
\text { one lung } \\
\text { both lungs } \\
\text { both lungs }\end{array}$ & $\begin{array}{l}\text { cardiac output } 4 \\
\text { cardiac output } 5 \\
\text { cardiac output } 6\end{array}$ \\
\hline $\begin{array}{c}\text { Halothane } \\
\text { H1 } \\
\text { H2 } \\
\text { H3 } \\
\text { H4 }\end{array}$ & $\begin{array}{r}50 \% \text { oxygen } \\
100 \% \text { oxygen } \\
100 \% \text { oxygen } \\
50 \% \text { oxygen }\end{array}$ & $\begin{array}{l}\text { both lungs } \\
\text { both lungs } \\
\text { one lung } \\
\text { one lung }\end{array}$ & $\begin{array}{l}\text { cardiac output } 7 \\
\text { cardiac output } 8\end{array}$ \\
\hline End expe & $\begin{array}{c}\text { ninutes after } \\
50 \% \text { oxygen }\end{array}$ & $\begin{array}{l}\text { ion of haloth } \\
\text { both lungs }\end{array}$ & cardiac output 9 \\
\hline
\end{tabular}

Blood was withdrawn as stated at each inspired oxygen concentration.

green dye dilution technique utilizing a Columbus cardiac output computer coupled to a Harvard constant infusion/withdrawal pump and to a direct writing X-Y plotter. Measurements were made in duplicate and only when the second output differed by more than two per cent of the first was a third measurement necessary. This occurred on only three occasions, attesting to the stability of the preparation. At the time of each sampling, systemic and pulmonary pressures were recorded and a permanent copy of the wave forms was made. These data were subsequently used to calculate the full range of frequently used cardiovascular parameters.

Ketamine was given at an induction dose of 2 $\mathrm{mg} \cdot \mathrm{kg}^{-1}$ by bolus intravenous injection and accurately maintained at $1 \mathrm{mg} \cdot \mathrm{kg}^{-1} / \mathrm{hr}$ using an IVAC 530 infusion pump for the duration of the relevant experimental period. A 30-minute period free of stimulation or challenge followed the cessation of ketamine infusion. Halothane was then introduced incrementally until a slight decrease in left atrial pressure occurred or to a maximum concentration of 1.5 per cent. If a drop in filling pressure was noted, the concentration was reduced by 0.2 per cent. Halothane percentage was adjusted by keeping left atrial pressure constant in an attempt to minimize decrease in cardiac output while at the same time maximizing the abolition of the hypoxic yasoconstrictor reflex. Calculation of the shunt fraction will be altered by any significant change in cardiac output. ${ }^{7}$ Once this percentage level of halothane was established, it was used for the duration of this portion of the study.

$\mathrm{PO}_{2}, \mathrm{PCO}_{2}, \mathrm{pH}$, base excess and standard base excess were measured and calculated using an ABL-1 machine. Shunt fraction was calculated using the original shunt equation:

$$
\mathrm{Qs} / \mathrm{Qt}=\frac{\left(\mathrm{CC}_{\mathrm{O}_{2}}-\mathrm{Ca}_{\mathrm{O}_{2}}\right)}{\left(\mathrm{CC}_{\mathrm{O}_{2}}-\mathrm{C}_{\mathrm{O}_{2}}\right)}
$$

utilizing Severinghaus correction factors.

$\mathrm{PO}_{2}$ values greater than 150 torr $(19.95 \mathrm{kPa})$ were corrected for linearity using the formula:

Actual $\mathrm{PO}_{2}=$ indicated $\mathrm{PO}_{2}\left(\left(\mathrm{PO}_{2}\right.\right.$ indicated $-150) \times 0.1)$

The oxygen content of pulmonary capillary blood, $\mathrm{CC}_{\mathrm{O}_{2}}$ was calculated by assuming that this would be the oxygen content that arterial blood would have if fully equilibrated with alveolar air. This is a standard assumption and necessary because of the inaccessibility of pulmonary capillary blood for direct measurement. The formulae used resulting from this assumption are as follows:

$$
\begin{aligned}
\mathrm{CC}_{\mathrm{O}_{2}}= & {\left[\mathrm{Sa}_{\mathrm{O}_{2}}(\mathrm{Hb} \times 1.39)+\mathrm{Pa}_{\mathrm{O}_{2}} \times 0.0031\right] } \\
& \mathrm{ml} / 100 \mathrm{ml} \text { blood } \\
\mathrm{PA}_{\mathrm{O}_{2}}= & \mathrm{PB}-\mathrm{Paco}_{2}-\mathrm{PH}_{2} \mathrm{O}-\mathrm{Pa}_{\mathrm{N}_{2}} \\
\mathrm{PA}_{\mathrm{N}_{2}}= & \text { partial pressure of nitrogen in the al- } \\
& \text { veolus determined by subtracting } \mathrm{Fl}_{\mathrm{O}_{2}} \\
& \text { from } 1 \text { and multiplying the resulting } \\
& \left(\mathrm{PB}-\mathrm{PH}_{2} \mathrm{O}-\mathrm{Pa}_{\mathrm{CO}_{2}}\right)
\end{aligned}
$$


TABLE II

Mean Values of Results With Standard Deviations

\begin{tabular}{|c|c|c|c|c|c|c|c|c|c|}
\hline & \multirow[b]{2}{*}{ Pulse } & \multicolumn{3}{|c|}{ Systemic Blood Pressure } & \multirow[b]{2}{*}{ PA } & \multirow[b]{2}{*}{ PAOP } & \multirow[b]{2}{*}{ CVP } & \multirow[b]{2}{*}{$\mathbf{Q}$} & \multirow[b]{2}{*}{ Qi } \\
\hline & & Systolic & Diastolic & Mean & & & & & \\
\hline $\mathrm{Cl}$ & $148 \pm 19$ & $141 \pm 18$ & $90 \pm 16$ & $108 \pm 14$ & $20 \pm 9$ & $13 \pm 9$ & $9 \pm 3$ & $4.1 \pm 0.9$ & $5.2 \pm 1.7$ \\
\hline $\mathrm{C} 2$ & $150 \pm 17$ & $140 \pm 10$ & $90 \pm 12$ & $104 \pm 10$ & $20 \pm 8$ & $11 \pm 3$ & $9 \pm 2$ & $4.1 \pm 0.9$ & $5.2 \pm 1.7$ \\
\hline $\mathrm{C} 3$ & $152 \pm 23$ & $147 \pm 13$ & $86 \pm 9$ & $107 \pm 10$ & $19 \pm 6$ & $12 \pm 3$ & $9 \pm 2$ & $4.2 \pm 1.1$ & $5.2 \pm 1.8$ \\
\hline $\mathrm{C} 4$ & $145 \pm 15$ & $142 \pm 16$ & $85 \pm 13$ & $106 \pm 14$ & $20 \pm 8$ & $12 \pm 6$ & $9 \pm 3$ & $3.7 \pm 1.3$ & $4.3 \pm 1.1$ \\
\hline $\mathrm{C5}$ & $147 \pm 12$ & $146 \pm 20$ & $91 \pm 14$ & $106 \pm 14$ & $19 \pm 7$ & $12 \pm 6$ & $8 \pm 2$ & $3.7 \pm 1.3$ & $4.3 \pm 1.1$ \\
\hline $\mathbf{K} \mathbf{1}$ & $137 \pm 18$ & $140 \pm 20$ & $88 \pm 21$ & $99 \pm 19$ & $20 \pm 9$ & $14 \pm 8$ & $9 \pm 5$ & $3.7 \pm 1.1$ & $4.4 \pm 0.9$ \\
\hline $\mathrm{K} 2$ & $137 \pm 16$ & $140 \pm 25$ & $88 \pm 18$ & $104 \pm 20$ & $21 \pm 9$ & $13 \pm 6$ & $11 \pm 4$ & $3.5 \pm 0.8$ & $4.2 \pm 0.6$ \\
\hline K3 & $138 \pm 13$ & $137 \pm 20$ & $89 \pm 11$ & $105 \pm 12$ & $16 \pm 4$ & $11 \pm 2$ & $9 \pm 2$ & $3.4 \pm 7$ & $4.2 \pm 1.2$ \\
\hline K4 & $133 \pm 14$ & $140 \pm 21$ & $92 \pm 14$ & $105 \pm 15$ & $17 \pm 6$ & $12 \pm 5$ & $9 \pm 2$ & $3.4 \pm 0.7$ & $4.2 \pm 1.2$ \\
\hline HI & $120 \pm 9$ & $122 \pm 12$ & $77 \pm 6$ & $89 \pm 7$ & $15 \pm 6$ & $11 \pm 5$ & $8 \pm 2$ & $2.9 \pm 0.8$ & $3.6 \pm 1.4$ \\
\hline $\mathrm{H2}$ & $115 \pm 15$ & $114 \pm 5$ & $72 \pm 15$ & $87 \pm 10$ & $15 \pm 5$ & $10 \pm 3$ & $8 \pm 2$ & $2.9 \pm 0.8$ & $3.6 \pm 1.4$ \\
\hline $\mathrm{H} 3$ & $116 \pm 19$ & $115 \pm 15$ & $70 \pm 12$ & $82 \pm 9$ & $17 \pm 7$ & $11 \pm 6$ & $10 \pm 6$ & $2.8 \pm 0.5$ & $3.5 \pm 0.8$ \\
\hline H4 & $123 \pm 21$ & $114 \pm 17$ & $68 \pm 13$ & $83 \pm 14$ & $18 \pm 8$ & $12 \pm 7$ & $10 \pm 6$ & $2.8 \pm 0.5$ & $3.5 \pm 0.8$ \\
\hline
\end{tabular}

PA = pulmonary artery pressure. PAOP = pulmonary artery occluded pressure. CVP = central venous pressure. $Q$ = cardiac output, $Q i=$ cardiac output indexed for body surface area.

Pressures are recorded as mm Hg (torr).

The Thal formula was used because the experimental design did not include measurement of the respiratory quotient. which is necessary if the more correct alveolar air equation is used. Alveolar oxygen saturation on 50 per cent and 100 per cent oxygen is assumed to be 100 per cent, satme as $D(A-a)_{O_{2}}{ }^{8}$

Throughout the experiment normothermia. normovolaemia and haematocrit were maintained.

\section{RESULTS}

The mean values and standard errors for each measured parameter are shown in Tables II and III.

\section{A. Shunt}

Average shunt fraction was higher by $6.50 \pm$ 2.51 under halothane than under ketamine anaesthesia - Table IV. The difference was statistically significant at the five per cent level by Student's t-test with five degrees of freedom. Yet more clearly significant contrasts were found for oxygen ( 100 per cent versus 50 per cent) $5.25 \pm$ 0.75 and for one lung versus two lungs $16.84 \pm$ 2.34. The basis of these tests was the consistency for the given factor among the six dogs. As shown in the table, the average shunt fraction in the four periods under one condition was subtracted from that for the four periods under the opposite condition, separately for each dog. The six resulting contrasts were averaged and their variance calculated to obtain the t-test. A more detailed form of statistical analysis, the analysis of variance. also shown in Table IV, gave consistent but more extensive results. Differences in average shunt fraction among dogs were statistically significant $(p<0.01)$. The three main factors were also significant by this analysis where in the case of the halothane versus ketamine contrast the significance level was $p<0.01$. Evidence that any of the three main factors affected the response to either of the other was tested for and found absent. None of the interaction terms was close to significance. Finally, the shunt fraction variance was $S^{2}=35.87$, reflecting a level of unaccountable variation per period in any dog of $\pm \mathbf{6 . 0}$.

B. Agreement between calculated shum fraction and $D(A-a)_{o_{2}}$.

In this small sample, a statistically significant but weak association between calculated shunt fraction and alveolar arterial oxygen concentration difference was shown. Table $V$ shows shunt fraction adjusted for $D(A-a)_{O_{2}}$ for individunl dogs during the eight sampling periods $\mathrm{K}_{1}$ through $\mathrm{H}_{4}$. (The adjustment, calculated by regression of shunt fraction on $\mathrm{D}(\mathrm{A}-\mathrm{a})_{\mathrm{O}_{2}}$ within dogs, pooled over the six dogs, was obtained by subtracting from shunt fraction the quantity 4.6 per cent of the deviation of the particular $D(A-a)_{\mathrm{O}_{2}}$ value from 331.0 , the average $D(A-a)_{O_{2}}$.) It is evident that differences of shunt fraction attributable to treatment were considerably less, as was the residual error term, among adjusted values. The overall reduction in variance was, in fact, 40 per cent. Nevertheless, highly significant differences 


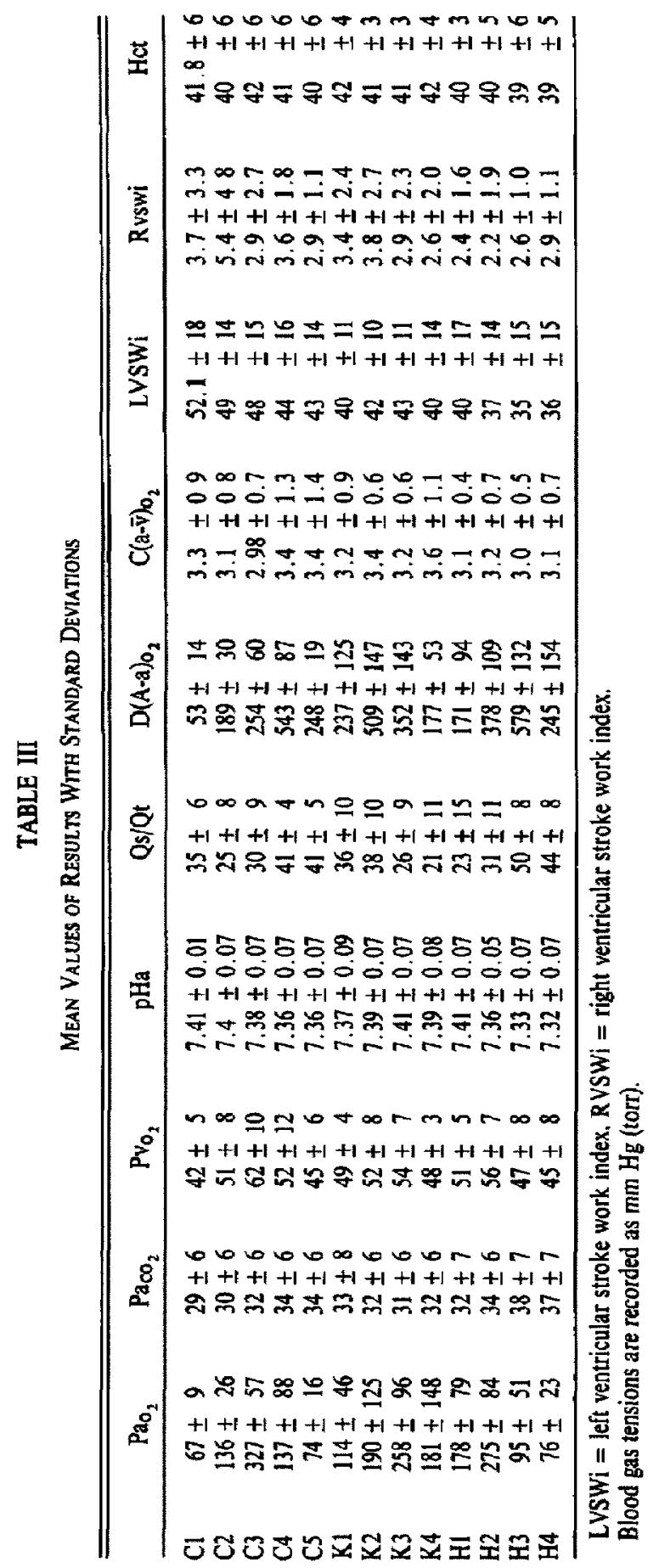


TABLE IV

Shunt Fraction

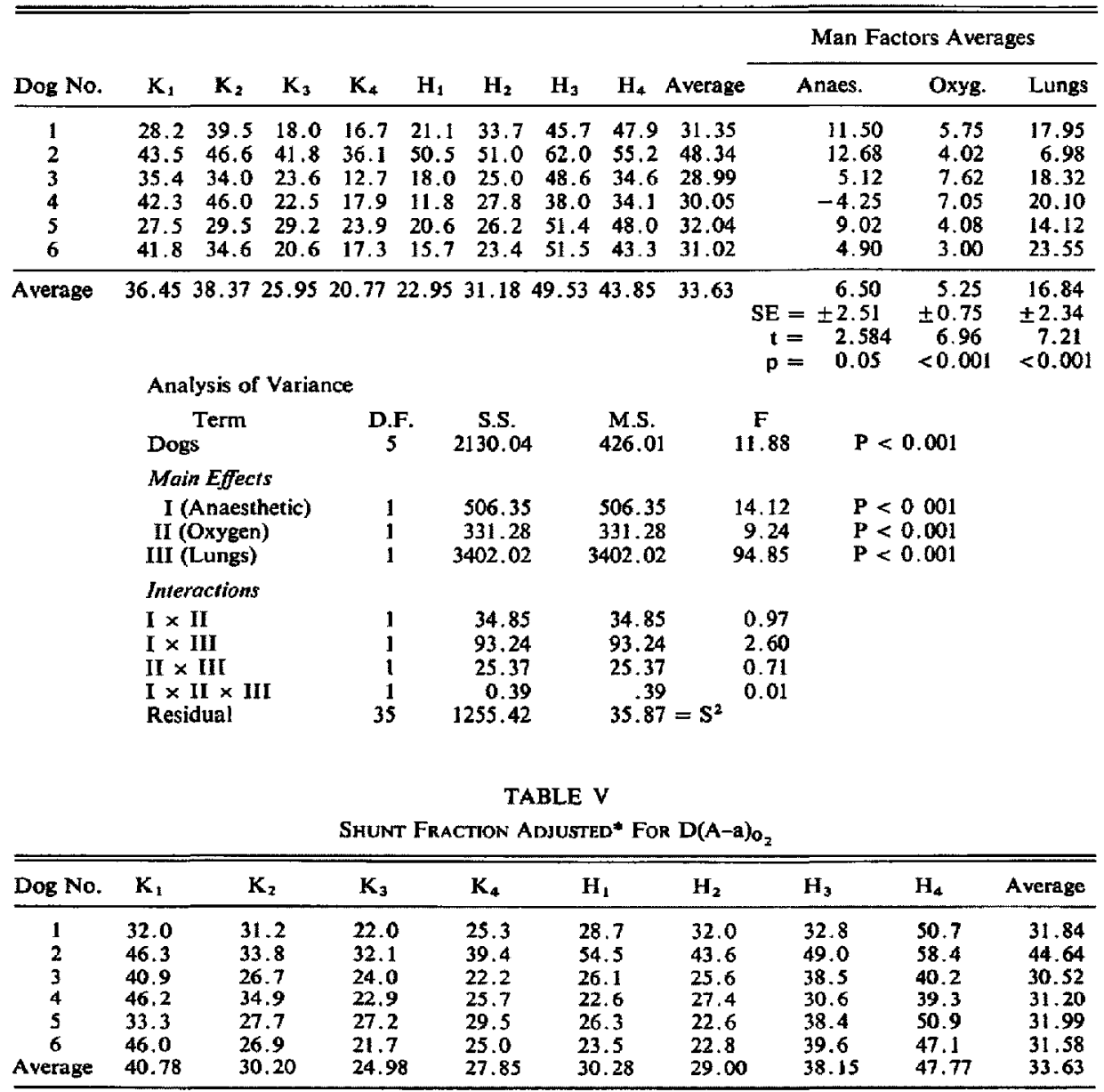

*Adjusted Shunt Fraction = Shunt Fraction -0.04589 (D(A-a) o $\left._{2}-330.9792\right)$, (see text). Analysis of Variance

\begin{tabular}{lcrrr}
$\quad$ Term & D.F. & S.S. & \multicolumn{1}{c}{ M.S. } & \multicolumn{1}{c}{ F } \\
Dogs & 5 & 1174.76 & 234.95 & 9.26 \\
Main Effects & & & & \\
$\quad$ I (Anaesthetic) & 1 & 342.94 & 342.94 & 13.51 \\
II (Oxygen) & 1 & 444.69 & 444.69 & 17.52 \\
III (Lungs) & 1 & 1504.16 & 1504.16 & 59.27 \\
Interactions & 4 & 252.34 & 63.08 & 2.49 \\
Residuals & 35 & 888.23 & $25.38=\mathrm{S}^{2}$ &
\end{tabular}

in average shunt fraction attributable to each of of shunt fraction, $D(A-a)_{O_{2}}$ appeared incapable of the three main factors of the experiment, reflecting all important changes. In this regard, anaesthetic administered, oxygen fraction and apparently $D(A-a)_{0_{2}}$ was more sensitive to the number of lungs were still present. As a predictor $\mathrm{FI}_{\mathrm{O}_{2}}$ and less sensitive to the factor of two versus 
one lung than the calculated shunt; hence the poor corrrlation.

It would seem from the trend observed that determination of shunt fraction by direct measurement of arterial and mixed venous samples is the only manner in which a true representation can be obtained during one lung anaesthesia. especially in instances when the $\mathrm{Pa}_{\mathrm{D}_{\mathrm{z}}}$ is less than $19.95 \mathrm{kPa}$ (150 torr).

\section{Discussion}

This study was designed to evaluate the effect of a continuous infusion of ketamine as an alternative to the more commonly used halothane during one lung anaesthesia. Changes in $\mathrm{PalO}_{2}$ and shunt fraction were chosen to delineate differences between agents, and attempts were made to eliminate all other variables. The abolition of the hypoxic vasoconstrictor reflex has been implicated by Sykes ${ }^{3}$ as a mechanism for the increase in shunt fraction during one lung anaesthesia. It is important to differentiate changes in shunt fraction due to anaesthetic agents from other influences such as differences in anaesthetic technique, changes in cardiac output. decrease in haematocrit, differing responses in the preparations or fatigue in the animals. Randomization of the order of anaesthetic challenges was eliminated by keeping the anaesthetic technique constant. If the order had been reversed in half the animals randomly, then it would be possible to exclude sequence, fatigue or preparation characteristics as causative or contributory factors toward the difference observed between anaesthetics. As it is, we can prove the difference statistically but cannot claim unequivocally that it was attributable only to the anaesthetics. However, even though the sequence was never reversed. in three dogs (numbers $I, 3$, and 6) a return to control conditions was permitted and, in all instances, the measured parameters returned to pre-ketamine levels and all animals appeared normally responsive within the limits of the preparation. Clear and statistically significant differences between runs were noted even though the sample size was small. Because the order of administration of ketamine followed by halothane was the same in all animals it is not possible to show that the differences were due to factors inherent in the comparison between ketamine and halothane.

Arterial hypoxaemia is also accentuated by atelectatic areas in a perfused dependent lung, secondary to a reduction in functional residual capacity and increase in airway closure. ${ }^{4.7}$ This effect was minimized by maintaining the animals in the supine position and continuing ventilation with no change in rate or tidal volume between one-lung and two-lung periods.

It can be seen that shunt fraction (see Table IV) is significantly greater in one versus two lungs. 100 versus 50 per cent oxygen, and halothane versus ketamine anaesthesia. These values are significant at the $p<0.05$ level and were calculated by comparing the average differences due to these factors against their standard errors in the six dogs. The results for one versus two lungs were expected and reports in the literalure substantiate the increased shunt in patients ventilated with 100 per cent oxygen, ${ }^{6}$ although some controversy over this finding has recently emerged. ${ }^{10}$

With the consistency in results in one versus two lung anaesthesia and 100 versus 50 per cent inspired oxygen, the increased shunt fraction during halothane as opposed to ketamine anaesthesia may be attributed to the inherent properties of these two anaesthetics. This conclusion rests on the consistency among dogs in the pattern of responses to the two agents under study. within the experimental framework. Any alternative explanation supported by a consistent pattern of variations among the six dogs would have been expected to appear in the analysis of variance for factor interactions. That analysis gave no suggestion of a fourth factor which could be responsible for the changes noted. However. as observed previously, the time sequence in application of halothane after ketamine in all dogs leaves open the question whether the effect here attributed to anaesthesia may have been produced in part by other time-related factors.

The order halothane following ketamine was chosen initially because it was felt that potentially beneficial effects on cardiac output consequent upon use of ketamine would, if anything, bias the experiment in favor of halothane. The myocardial depressant effects of halothane could also have lasted longer than the time permitted for the experiment. Neither of these effects was noted, however, and the rapid return of cardiac output to pre-ketamine levels in dogs 1,3 and 6 supports the contention that further experimentation should be performed with randomization of anaesthetic challenges.

It is shown that during one lung anaesthesia, $D(A-a)_{O_{2}}$ has no consistent relationship to the calculated shunt fraction. Therefore, if accurate 
calculation of the shunt is indicated. direct pulmonary artery sampling will be required.

Stabilization of cardiac output was an obvious goal throughout the experiment and this became very difficult during halothane anaesthesia. As has been previously stated, changes in cardiac output will definitely change shunt calculations? and yet, even though output progressively fell throughout the procedure, filling pressures and haematocrit were well maintained. The fact that cardiac output returned to pre-ketamine levels at the end of the experiment in three animals also supports the contention that a direct myocardial depressant effect of halothane contributes to arterial hypoxaemia and calculated shunt. However. the analysis of variance for individual factor interactions does not show which property of halothane exerts the major influence in the increased shunt observed; but without infusion of an appropriate inotropic agent during the halothane runs the answer to this question will necessarily be postponed for further experimentation. Maintenance of left atrial filling pressure was initially thought to be an acceptable means of supporting cardiac output with definite clinical application during operations. For this reason a decrease in filling pressure called for a reduction in halothane concentration with a concomitant increase in forward loading until stability was obtained and maintained for 15 minutes before measurement of any physiological variables. It was assumed that the maximum tolerated halothane concentration under the above conditions would result in the maximum obtainable halothane effect on the hypoxic vasoconstrictor reflex consistent with the experimental conditions.

In future experiments, further elaboration of these anaesthetic effects will hopefully be demonstrable by radioactive isotope studies of the lungs and pulmonary vessels during comparisons of halothane and ketamine anaesthesia under similar experimental conditions.

\section{SUMMARY}

It has been shown that a continuous infusion of ketamine during one-lung anaesthesia combined with a 50 per cent oxygen-curare anaesthetic technique will provide consistently lower shunt fraction and higher $\mathrm{Pa}_{\mathrm{O}_{2}}$ compared with halothane under the same experimental conditions.

Because no additional factor was observed which could account for these changes and because the responses of the animals to the two anaesthetic agents were similar - the only difference being a different initial set point - the experimental model may be considered adequate. In the authors' view the difference in shunt fractions may be attributed to a more stable hypoxic reflex during ketamine anaesthesia.

Further experimentation will be necessary to fully exclude the possibility of sequence-related changes affecting some of these results and to determine whether or not certain groups of dogs respond in a qualitatively different fashion.

\section{RÉSUMÉ}

Ce travail a démontré qu'une infusion continue de kétamine associée à une anesthésie par inhalation au moyen de protoxyde d'azote à $S 0$ pour cent chez des chiens curarisés assurait de façon constante une $\mathrm{Pa}_{\mathrm{O}_{2}}$ supérieure et un shunt moindre par comparaison aux résultats observés lorsque l'anesthésie était effectuée avec un mélange de protoxyde d'azote à 50 pour cent d'halothane et oxygène, ceci en situations de poumon exclu (tube endotrachéal poussé dans une bronche et ballonnet gonflé). Ces résultats semblent dus à un réflexe de vasoconstriction à l'hypoxie mieux conservé sous anesthésie à la kêtamine. Les auteurs estiment cependant nécessaire de poursuivre leur étude afin de confirmer leur conclusion.

\section{ACKNOWLEDGEMENTS}

The authors acknowledge with thanks Dr. R.S. Litwak for his support of this project, Ms. V. Scharf for technical assistance, and Mr. D. Calhoun of G.D. Searle, Chicago, Illinois, for invaluable help with the statistical analysis.

\section{REFERENCES}

1. Thomson, D.F., and CAmpbel., D. Changes in arterial oxygen tension during one-lung anesthesia, Brit. J. Anaesth. 45:611-616 (1973).

2. DRUMMOND G.B. WILDSMITH, A.W. \& MASSON, H.B. Impairment of oxygen transfer in the lung by increasing oxygen concentration during halothane and trichlorethylene anaesthesia. Brit. J. Anaesth. 50: 255 (1978).

3. Sykes, M.K. Loh, L. . Seed, R.F.. Kafer, E.R \& CHakrabarT!, M.K. The effect of inhalational anaesthetics on hypoxic pulmonary vasoconstriction and pulmonary vascular resistance in the perfused lungs of the dog and cat. Brit. J. Anaesth. 44: 776 (1972).

4. Nunn, J.F. Williams. I.P. \& Jones, J.G. Detection and reversal of pulmonary absorption collapse. Brit. J. Anaesth. 50:91-100 (1978).

5. Khanam, T. \& Branthwaite. M.A. Arterial 
oxygenation during one-lung anaesthesia. Anaesth. 28: 132-138 (1973).

6. TARHAN, S. \& LundborG, R.O. Effects of increased expiratory pressure on blood gas tensions and pulmonary shunting during thoracotomy with use of the carlens catheter. Canad. Anaesth. Soc. J. 17: 4-11(1970).

7. KERR, John J. Physiological aspects of one-lung (endobronchial) anaesthesia. Int. Anesth. Clin. 10: No. 4 (1972).

8. Vinocur. B., ARTz, J.S. \& SAMPLINER, J.E.
Monitoring of respiratory status. Handbook of Critical Care, Berk, J.L. Sampliner, J.E. Artz. J.S, Vinocur, B. Eds., Little, Brown Pubs. (1976). 9. Shapiro, A.R. \& Peters. R.M. Interpictation of alveolararterial oxygen tension difference. Surg. Gynec. Obst. 144: 547-552 (1977).

10. Tonnesen, A.S. Gabel. J.C.. Guidry, O.F., Drake. R.E.. ARENS. J.F. Lack of Effect of $100 \%$ $\mathrm{O}_{2}$ breathing on Shunt. Abstracts of Scientific Paper's 1977 A.S.A. annual meeting. pp. 13-14. 